\title{
How to Become a Competitive Applicant for Gastroenterology Fellowship: Tips and Tricks for Success Part I
}

\author{
Nikki Duong ${ }^{1} \cdot$ Elizabeth S. Aby ${ }^{2} \cdot$ Kelly E. Hathorn ${ }^{3} \cdot$ C. Roberto Simons-Linares ${ }^{4} \cdot$ Mohammad Bilal $^{5}$
}

Published online: 30 April 2020

(c) Springer Science+Business Media, LLC, part of Springer Nature 2020

\begin{abstract}
In recent years, gastroenterology has become one of the most competitive subspecialties included in the internal medicine fellowship match, which increases the stressful nature of an already potentially nerve-wracking process for the trainee. Though each applicant has unique strengths and thus the process is somewhat individualized, there are some basic principles that can render an applicant more competitive for a gastroenterology fellowship. These include establishing mentorship, achieving scholarly work, building your resume, honing interpersonal and networking skills, and a writing a well-planned application. The goal of this article is to outline some basic principles that will help improve the competitiveness of an applicant, and also highlight some practical tips and tricks for applicants with diverse backgrounds, such as international medical graduates, minority applicants, and women in medicine.
\end{abstract}

\section{Introduction}

Over the past few years, gastroenterology (GI) has become one of the most competitive subspecialties included in the internal medicine fellowship match [1-3]. In data published by the National Resident Matching Program (NRMP) in 2019, there were 908 applicants for 577 first-year GI fellow positions [4]. In a 2016 survey of fellowship program directors, the three most important factors in selecting applicants for interview were evidence of professionalism, residency performance evaluations, and letters of recommendation

Nikki Duong

Nduong91@gmail.com

1 Department of Internal Medicine, Georgetown University Hospital, 3800 Reservoir Rd NW, Washington, DC 20007, USA

2 Division of Gastroenterology, Hepatology and Nutrition, University of Minnesota, 500 SE Harvard St, Minneapolis, MN 55455, USA

3 Division of Gastroenterology, Hepatology and Endoscopy, Brigham and Women's Hospital, Harvard Medical School, 75 Francis Street, Boston, MA 02115, USA

4 Department of Gastroenterology, Hepatology and Nutrition, Cleveland Clinic, 9500 Euclid Avenue, Cleveland, OH 44195, USA

5 Division of Gastroenterology, Hepatology and Nutrition, Beth Israel Deaconess Medical Center, Harvard Medical School, 330 Brookline Avenue, Boston, MA 02215, USA in the fellowship specialty, whereas the top three factors in ranking applicants were interview day interactions with faculty and trainees, interpersonal skills, and evidence of professionalism [5]. The goal of this article is to outline some basic principles that will help make an applicant competitive, and also highlight some practical tips and tricks for applicants with diverse backgrounds, such as international medical graduates, minority applicants, and women in medicine.

This article is divided into two parts, with this first part devoted to helping with important decisions such as deciding on a career, ensuring that you have made the correct choice, finding and selecting a mentor or mentors and/or promoter(s), and engaging in scholarly research.

\section{Deciding on a Career}

Some trainees begin residency knowing that they want to become gastroenterologists, while others might begin residency with an open mind and an undecided career path. Some trainees know from the beginning that they have a strong interest in a specialty in which they can perform procedures, whereas some just might not know what they want to do at all. If you have any inclination toward applying for a GI fellowship, it never hurts to get started working on projects or reaching out to mentors in GI early in your residency career. Nevertheless, with that being said, there are certainly 
situations in which applicants come to a decision that they want to pursue a GI fellowship later in their residency training. Although it may impact the amount of scholarly work you have done in the field of GI prior to submission of your fellowship application, it is a part of your personal story in "your career in GI" and should not discourage you from pursuing your passion.

\section{Self-Assessment}

The first step in this process is self-assessment. This does not have to be a long process, but requires only a few days to self-reflect. As mentioned above, GI is one of the most competitive specialties, so it is important to determine your strengths and weaknesses. Although residents cannot alter past factors such as USMLE scores, their medical school attended, current residency program, visa status, and IMG status, they can control their scholarly work output, the faculty writing their support letters, and certain aspects of their CV. Although personalities can be difficult to change, appropriate effort and coaching can be helpful for building one's reputation/brand, achievement of professional growth, and gaining interpersonal skills. Once you have identified your modifiable factors, it is time to get started building upon your strengths and minimizing your weaknesses. It is also important to note that the process of self-assessment should be a dynamic process, i.e., one should self-reflect to assess their strengths and identify areas of improvement every few months.

\section{Finding a Mentor and/or Promoter}

Mentorship is essential to academic success and professional growth. Despite this, it is not always easy to find the appropriate mentor. There are several types of mentors, and most of us through various points in our careers have multiple mentors that serve different purposes. You may need several different mentors to help strengthen your own professional growth. Mentors can come in all shapes and sizes, ranging from research mentors to career mentors to inspirational mentors to peer mentors.

A research mentor is one of the most important mentors for those applying to GI fellowship since scholarly work is an integral part of the fellowship application. When selecting a research mentor, it is important to find someone who not only shares research interests with you, but also has the time and energy to mentor a trainee. A great mentor is enthusiastic, approachable, invested in your own success, and understands your timeline. A great mentor has an impressive track record in mentoring prior trainees. There is no right or wrong, but it is important to know what you are looking for when you choose a mentor. While working with a leader in a field may provide certain opportunities, these mentors may not have substantial amounts of time to dedicate to developing a trainee's research interest and projects. On the other hand, a young faculty member who is more easily accessible may be a better fit when looking to develop research skills, but may not have the national and international connections that a more experienced mentor can provide. Senior faculty can be excellent mentors for inspiring you and can help facilitate connections. Since senior mentors have experience and personal knowledge in key aspects of academia such as familiarity with society leadership, journal editors, grant review committee members, and program directors, these faculty can provide valuable inside information and connections regarding publishing your work, presenting it at national meetings, and obtaining grant support in addition to providing insight into GI fellowship programs and their involved personalities. It is thus important to seek out and obtain the advice of the senior mentors at your institution, who can be essential in connecting you to other mentors or providing other opportunities at the national level, such as involvement in national GI organizations.

Part of creating a fruitful mentor-mentee relationship is understanding and embodying the qualities of a good mentee. At the start of a relationship, define your specific needs and goals with your prospective mentor; this enables them to get a sense of how they can help you in development of your career. When working with your mentor, the best strategy is to under-promise and over-deliver since this will strengthen the impression that you are dedicated, hardworking, and can deliver. These qualities improve your mentee-mentor relationship, and your own academic growth. As outlined by Elliot Tapper and Neil Sengupta, the "art of mentoring" includes introspection, persistence, and teamwork [6]. In addition to mentorship relationships with faculty, it is often helpful to foster peer or near-peer mentorship to promote your growth.

US residency programs that do not have internal fellowship or GI programs can pose additional challenges in finding mentors and opportunities for scholarly work. In this situation, you should seek mentors at other institutions. Being a part of national societies, such as the American College of Gastroenterology (ACG), American Gastroenterological Association (AGA), and the American Association for the Study of Liver Diseases (AASLD), provides opportunities for choosing mentors at outside institutions. You should also consider an "away rotation" at an institution where a GI fellowship program exists. The away rotation can broaden your exposure within the field of GI, connect you to external mentors (including potential letter writers), and provide new opportunities for research. Even if your rotation is short, this experience opens the door for research and networking 
opportunities that you can build on throughout residency and beyond.

Lastly, it is important to recognize the difference between a mentor and promoter. A mentor will help guide you as mentioned above, but a promoter will advertise for you and create opportunities for you in leadership and academic positions.

\section{Research/Scholarly Work}

Although there is no magic number of papers or projects that is required to match, scholarly work is an essential component of the fellowship application. Given that admission to GI fellowship is extremely competitive, and many exceptional residents with stellar recommendations apply, scholarly work becomes a surrogate marker for a resident's motivation to pursue a career in academics.

Given the busy clinical schedule of residency, it is not generally expected that residents will be deeply involved in the conduct of randomized clinical trials during residency. When choosing to be involved in scholarly work, talk with residents and fellows about which mentors are best for trainees; these conversations can provide valuable insight. When it comes time to commit to a project, make sure it is feasible for your level of training, fits within your timeline, and will produce at least one abstract, preferably presented at a national meeting, and at least one full-length publication. Approaching mentors with your pre-defined skill set helps them determine the best project for you. For instance, some trainees may want to start with a chart review project, while others might be proficient in writing or have some statistical experience [7]. Regardless, once you get a project, no matter how small or big it is, this is your time to prove yourself. Ideally, you will design and complete a project based on your own original hypotheses. Short of that, your main charge is to complete the tasks given to you in the most reliable and efficient manner possible. This will build your reputation as a reliable resident and can open the door to other opportunities and projects in the future.

The time between the start of intern year and submission of your gastroenterology application is roughly 24 months. Nevertheless, during your intern year due to the clinical schedule, it can be difficult to be actively involved in research projects. Thus, it is important to have projects that are feasible and can be completed in time for your application. Keep the submission deadlines of the major GI conferences, including national meetings sponsored by the ACG, AASLD, and DDW, in mind, and plan your projects accordingly. The opportunity to present your research at conferences not only boosts your resume, but also allows you to get feedback on your research. These conferences also provide excellent networking opportunities. All national gastroenterological societies are very receptive to traineeinitiated work, including case reports or series, quality improvement projects, and retrospective studies. It is important to be on the lookout for interesting cases for case report publications as well; one tip is that you can ask GI fellows and attendings whether they need help in writing up their interesting cases, given that many may not have the time to do so themselves and would appreciate your assistance.

It is usually advisable to have one project of your own serving as your main focus, while also continuing to work on case reports, review articles, or even additional research projects with others in which you may make a smaller contribution. For residents who do not have mentors at their own institution, scholarly work such as writing review articles or helping with meta-analyses and systematic reviews are good ways to engage in projects with mentors at outside institutions, since these types of projects do not require that you have access to a particular institution's resources or medical records. Also, do not be afraid to collaborate with multiple residents on the same project, as long as the contributions and authorship criteria are clearly defined from the outset.

Another avenue for scholarly work is volunteering to review for journals. For instance, the ACG case reports journal has opportunities for residents to review case reports, which not only builds your resume, but also helps gain valuable experience about the peer-review process.

Authors' contributions ND and MB were involved in concept design and drafting of the manuscript. EA, KEH and CRSL wrote critical portions of the manuscript and provided expert opinion. All authors contributed to the manuscript.

Funding None with respect to this manuscript.

\section{Compliance with Ethical Standards}

Conflict of interest The authors report no conflict of interest and have no financial disclosures with respect to this manuscript.

\section{References}

1. Decross AJ, Proctor DD. The process of applying for gastroenterology fellowship. Gastroenterology. 2012;142(7):1405-1408.

2. Huang RJ, Triadafilopoulos G, Limsui D. The gastroenterology fellowship match: a decade later. Dig Dis Sci. 2017;62(6):1412-1416.

3. Niederle M, Roth AE. The gastroenterology fellowship match: how it failed and why it could succeed once again. Gastroenterology. 2004;127(2):658-666.

4. Program National Resident Matching. Charting Outcomes in the Match, Specialties Matching Service, Appointment Year 2018. Washington, DC: National Resident Matching Program; 2018.

5. National Resident Matching Program, Data Release and Research Committee. Results of the 2016 NRMP Program Director Survey, 
Specialties Matching Service. Washington, DC: National Resident Matching Program; 2016.

6. Tapper EB, Sengupta N. How to succeed in research during fellowship: what the trainee needs to do (and needs from the program). Gastroenterology. 2017;152(5):922-925.

7. Bilal M, Hernandez-Barco YG, Parupudi S, Sonstein L, Szauter $\mathrm{K}$, Powell DW. Institution of a novel curriculum increases scholarly output among internal medicine residents. Dig Dis Sci. 2020;65:937-941.
Publisher's Note Springer Nature remains neutral with regard to jurisdictional claims in published maps and institutional affiliations. 